\title{
EVALUATION OF AN ELECTRIC TURBO COMPOUND SYSTEM FOR SI ENGINES: A NUMERICAL APPROACH
}

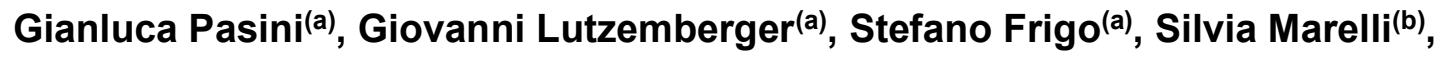
Massimo Ceraolo(a), Roberto Gentili(a), Massimo Capobianco(b) $^{(\mathrm{b}}$
a) University of Pisa - DESTEC
Largo Lucio Lazzarino
56122 Pisa (ITALY)
Tel. $\quad+39-050-2217100$
Fax $\quad+39-050-2217150$
b) University of Genoa - DIME
Via Montallegro, 1
16145 Genoa (ITALY)
Tel. +39-010-3532443
Fax +39-010-3532566

\section{Corresponding Authors:}

\section{Gianluca Pasini}

Department of Energy, System, Territory and Construction Engineering (DESTEC)

University of Pisa

Largo Lucio Lazzarino

56122 Pisa (ITALY)

Tel. +39-050-2217161

Fax +39-050-2217150

Email gianluca.pasini@for.unipi.it 


\section{ABSTRACT}

In a medium term scenario hybrid powertrain and Internal Combustion Engine (ICE) downsizing represent the actual trend in vehicle technology to reduce fuel consumption and $\mathrm{CO}_{2}$ emission. Concerning downsizing concept, to maintain a reasonable power level in small engines, the application of turbocharging is mandatory both for spark ignition ( $\mathrm{SI}$ ) and compression ignition ( $\mathrm{Cl}$ ) engines. Following this aspect, the possibility to couple an electric drive to the turbocharger (electric turbo compound) to recover the residual energy of the exhaust gases is becoming more and more attractive, as demonstrated by several studies around the world and by the current application in the F1 Championship.

The present paper shows the first numerical results of a research program under way in collaboration between the Universities of Pisa and Genoa. This first study is focused on the evaluation of the benefits resulting from the application of an ETC to a small twin-cylinder SI engine $\left(900 \mathrm{~cm}^{3}\right)$. Starting from the experimental maps of two turbines and one compressor, the complete model of a turbocharged engine was created using the AVL BOOST one-dimension code. The numerical activity then moves to the whole vehicle/powertrain modelling, considering three driving cycles and two different vehicle configurations, in order to verify the effectiveness of the proposed ETC solution.

Results show that ETC is not beneficial over a conventional turbocharger with appropriate turbine geometry if the target is to optimize the overall efficiency in one specific operating point of the ICE, like in the case of range-extended electric vehicles. Besides, ETC can slightly improve the average overall efficiency when the ICE must provide variable power output, as in the case of conventional or hybrid vehicles. However, the major benefits coming from ETC are the boost range extension in the lowest engine rotational speed region and a possible reduction of turbo lag, which are key points in parallel-hybrid and especially in conventional vehicles.

Concerning the whole vehicle/powertrain simulation, first results show that the ETC does not improve fuel economy of the smaller vehicle, especially when employed in urban cycles. The ETC is much more advantageous in the case of the larger vehicle, particularly when extra-urban roads or motorways are considered.

KEYWORDS - Internal Combustion Engines, Exhaust gas energy recovery, Turbocharger flow maps, Electric Turbo Compound, Hybrid Vehicle, Electric Vehicle. 
80 


\section{Introduction}

107

108

109

110

111

112

113

114

115

116

117

118

119

120

121

122

123

124

125

126

127

128

129

130

131

132

133

134

135

136

137

138

139

140

141

142

143

144

145

146

147

148

With growing concern for environmental problems, in the last years more stringent standards for vehicle fuel consumption and emissions have been introduced. Therefore, vehicle manufacturers focused their attention on the development of modified conventional vehicles in hybrid versions. These vehicles have advanced powertrains for efficient utilization of energy, in order to recover energy during braking and allow the Internal Combustion Engine (ICE) to operate on its highest efficiency region. Additionally, depending on the hybrid powertrain typology (i.e. series hybrid, parallel hybrid, range extended, etc.), the ICE can also be significantly downsized.

In this regard, to maintain a reasonable power level in small ICEs, the application of turbocharging (TC) technology is mandatory, both for spark ignited ( $\mathrm{SI}$ ) and compression ignited (Cl) engines. To this aim, the possibility to couple an electric drive to the turbocharger (Electric Turbo Compound, ETC) to recover the residual energy of the exhaust gas, as well as to extend the boost range and reduce the turbo lag, is becoming more and more attractive, as demonstrated by several studies around the world and by the current application in the F1 Championship.

This approach belongs to a wider topic, which is the maximum recovery of the residual energy from the exhaust gas to regenerate it either within the engine crankshaft or within auxiliary powertrain units inside the vehicle. Without entering into details, which are well explained in the recent open

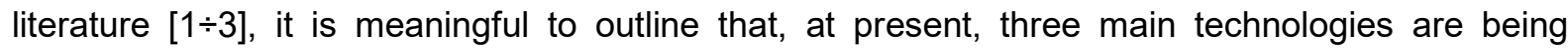
studied for exhaust energy recovery in the automotive sector, i.e., ORCs (Organic Rankine Cycles), thermoelectric generators and turbo compounding.

The Organic Rankine Cycles offer waste heat recovery without imposing any additional backpressure to the engine as it does not restrict the exhaust gas flow leaving the engine. Despite a potential improvement in BSFC (Brake Specific Fuel Consumption) of as much as 15\%, the implementation of ORCs requires a complex engineering architecture, which makes it not suitable for small-scale applications such as passenger vehicles [4-10].

Similarly, thermoelectric generators do not increase exhaust back-pressure. The principle of thermoelectric generation relies on the Peltier-Seebeck effect which accounts for the direct conversion of thermal energy into electric energy. Nevertheless, the efficiency of electric conversion is poor and requires large surface areas which are not always available in automotive applications. Besides, the cost of the material for thermoelectric generator devices is still high, thus this technology is not yet practical for commercialisation $[11 \div 15]$.

The last method to recover exhaust gas energy from ICEs is represented by the adoption of turbocompounding technology. Turbocompounding consists in the addition of a mechanic or electric device to the main turbocharger turbine in order to recover the excess of energy available in the exhaust.

Mechanical turbocompounding technology [16-19] involves the installation of a power turbine besides the Turbocharger (TC) turbine for extracting mechanical power from the exhaust gas stream. Mechanical turbocompounding is well known for being used on aircraft engines in the 1950's. The three most successful and documented engines are the Wright R-3350, the Napier Nomad and the Allison V-1710. Today, mechanical turbocompounding is mainly used on large displacement diesel engines designed for use in heavy ground vehicles such as trucks and agricultural equipment adopted, for example, by Scania, Volvo and Detroit Diesel. 
The electrical turbocompounding strategy is based on two configurations: in the first layout an additional turbine is placed on the exhaust line, usually downstream of the turbocharger turbine, linked to a small electric generator (turbo generator) [20 22$]$. The second configuration is based on coupling an electrical generator to the TC shaft for extracting excess power produced by the

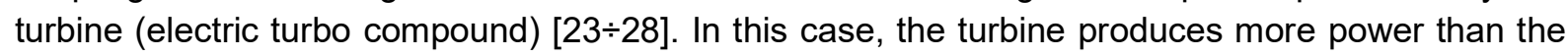
necessary to drive the compressor. The excess power is converted into electric power using a high speed generator incorporated in the TC casing. The electrical drive can be also used to accelerate the TC shaft and reduce the turbo lag, despite the overall increased inertia. An alternative solution is the use of a turbine and a compressor without mechanical link, both with individual electric drive.

In the present paper, the first numerical results of a joint research program developed by the Universities of Pisa and Genoa are shown. Very few papers present studies related to the application of an ETC to SI engines $[28,29]$ and no one has been made adopting the numerical codes here applied.

In the first part of the study, the evaluation of the benefits resulting from the application of an ETC to a small-size twin-cylinder S.I. engine has been examined. In particular, utilizing the AVL BOOST-1D computational program, implemented with experimental turbocharger characteristic curves, an estimation of the global amount of the energy recovered from exhausts is predicted, providing further insights into engine operating range where ETC is beneficial with respect to a conventional TC and giving hints on how to size the turbine geometry to maximize the recovered energy. Concerning this last aspect, some Authors noted the importance of choosing a power turbine flow capacity large enough to avoid high backpressure penalties, even if slight or no effect on fuel consumption occurs [29].

In the second part of the study, the numerical activity moves to the whole vehicle/powertrain modelling adopting the 3DS's Dymola code based on Modelica language. Engine results are utilized to identify the optimal way to exploit the electrical energy recovered. Vehicle powertrain architecture of a conventional vehicle equipped with a standard TC group is kept unmodified as much as possible, as well as that of the electrical system, apart the introduction of the ETC device. Three driving cycles and two different vehicle configurations have been analysed. The three driving cycles, all from CADC (Common Artemis Driving Cycle), are able to represent the vehicle usage in urban, extra-urban roads and motorways in a realistic way.

\section{Experimental results on turbocharger performance}

Turbine and compressor maps implemented in the engine simulation model are properly selected referring to an experimental database available at the Internal Combustion Engines Group (ICEG) of the University of Genoa. In particular, two turbines and one compressor are identified. Both turbines are single entry nozzleless radial flow units, fitted with a waste-gate valve. The first turbine (Garrett GT2052, called A) is characterized by $47 \mathrm{~mm}$ rotor diameter and by a TRIMt level equal to 0.72 , the second (IHI RHF3, called $\mathrm{B}$ ) by a rotor diameter of $33 \mathrm{~mm}$ and by a TRIMt equal to 0.81 . Selected compressor is a radial flow type (IHI RHF3) characterized by an impeller diameter of about $40 \mathrm{~mm}$.

Experimental characteristic curves of the turbomachines have been measured at the turbocharger test facility of the University of Genoa (Figure Fig. 1), fully described in previous papers [30, 31, 32]. The compressed air apparatus is fitted with three electrical screw compressors able to provide a total mass flow rate of about $0.6 \mathrm{~kg} / \mathrm{s}$ at a maximum pressure of 8 bar. An electric heater allows 
increasing turbine inlet temperature up to $750{ }^{\circ} \mathrm{C}$. However, turbine experimental maps here selected refer to an inlet air temperature of about $80^{\circ} \mathrm{C}$ ("cold operation").

Even if experimental results here reported refer to turbine and compressor steady flow characteristic curves, it must be mentioned that the possibility to reproduce the unsteady flow typically occurring in the intake and exhaust engine circuit is a peculiarity of the UNIGE test facility. In particular, two different arrangements respectively using diametral slot rotating valves or a motor driven cylinder head are available, fully described in [30, 33].

Measurements are performed by an automatic data acquisition system, using interactive procedures in LabVIEW $^{\circledR}$ environment. All quantities here reported are an ensemble average of multiple data acquisition (10 cycles). Therefore, measurements are referred to the average level of data recorded at the same operating condition. Under steady flow condition, static pressure levels are measured at the inlet and outlet section of compressor and turbine through strain-gauge transducers characterized by an accuracy of $\pm 0.15 \%$ of the full scale. A high frequency response piezoresistive pressure sensor mounted just downstream of the compressor volute exit is used to measure instantaneous pressure signal to detect surge phenomenon [30]. Total air temperature levels are measured through platinum resistance thermometers ( $\mathrm{Pt} 100 \mathrm{Ohm}$ ) with a measurement tolerance of $\pm 0.15{ }^{\circ} \mathrm{C}+0.2 \%$ of measured value. All sensors are crosswise inserted in the flow pipe. With particular reference to the compressor outlet section, three different probes are generally adopted to evaluate compressor efficiency (therefore turbine thermo-mechanical efficiency) with good accuracy. Turbocharger rotational speed is measured by an inductive probe mounted close to the compressor wheel allowing to detect rotor revolution with good accuracy. Compressor mass flow rate is measured through a thermal mass flow meter with a measurement tolerance of $\pm 0.9 \%$ of measured value and $\pm 0.05 \%$ of the full scale. As regards turbine mass flow rate, this quantity is measured through a laminar flow meter (measurement tolerance of $\pm 2 \%$ of measured value).

In Figure 2 steady flow characteristic curves of both considered turbines measured at different levels of rotational speed factor ranging from 2000 to $7000 \mathrm{rpm} / \sqrt{\mathrm{K}}$ are shown. Turbine maps are referred to the complete closure of the by-pass system (waste-gate valve), since only turbine maps with the regulating device fully closed are implemented in the simulation model. Since results here reported are measured in "cold conditions", all quantities are scaled based on the conventional non-dimensional groups to properly take into account for the density variation of the flow entering the turbine.

Turbine maps are then referred to the following parameters:

- turbine rotational speed factor: $\quad[\mathrm{rpm} / \sqrt{\mathrm{K}}]$

$$
N_{t}=\frac{n}{\sqrt{T_{T 3}}}
$$

- Expansion ratio (total-to-static):

$$
\varepsilon_{T S}=\frac{p_{T 3}}{p_{S 4}}
$$




$$
\Phi_{t}=\frac{M_{t} \cdot \sqrt{T_{T 3}}}{p_{T 3}}
$$

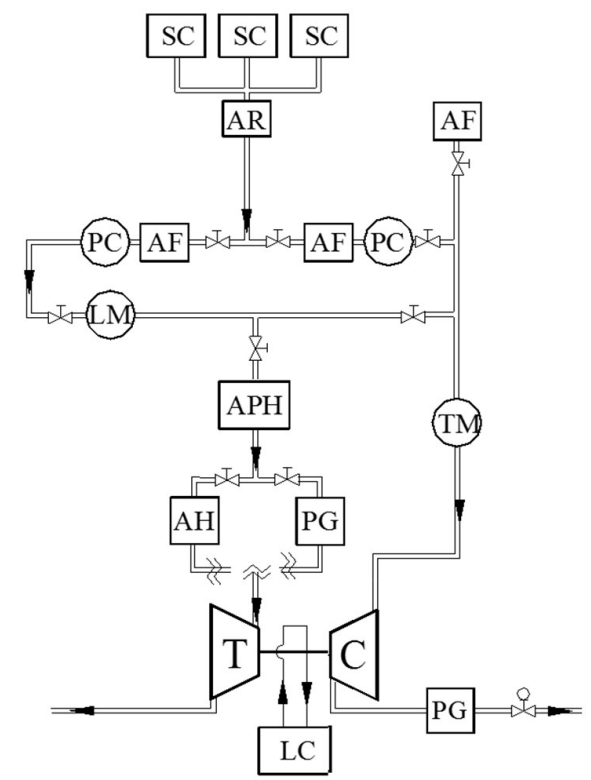

Fig. 1: Turbocharger test facility of University of Genoa.

In order to measure turbine characteristic curves over an extended range while keeping the turbocharger compressor coupled, modulation of compressor inlet pressure is performed, thus controlling its power absorption, working at higher and lower level than the ambient condition. In Figure 2 it is highlighted that mass flow rate factor is more sensitive to the expansion ratio than to turbine rotational speed at constant waste-gate valve setting. It is worth noticing the extension of each constant speed curve that was achieved at low turbine inlet temperature (about $400 \mathrm{~K}$ ). The definition of steady flow curves in a wide operating range is an essential requisite to reduce inaccuracies in the extrapolation method adopted within simulation models. 


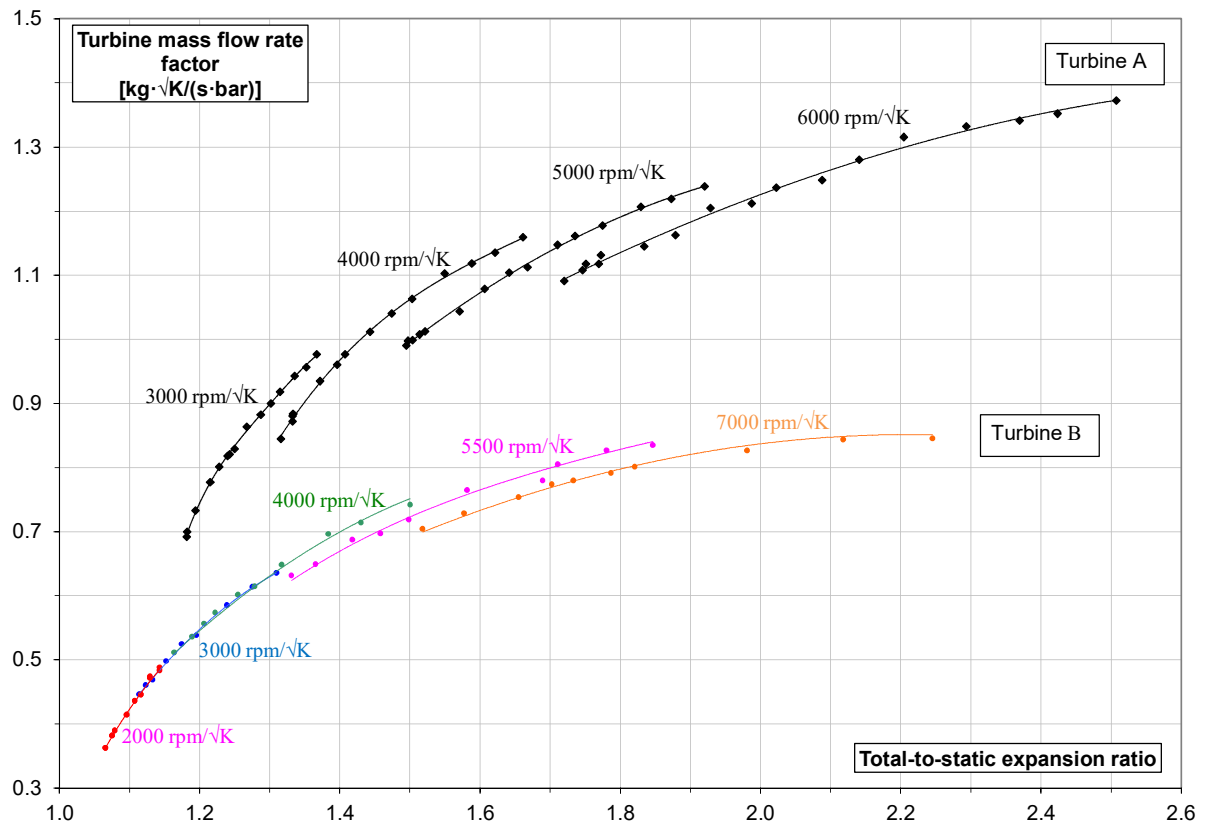

Fig. 2: Measured turbine steady flow maps.

As aforementioned, the compressor selected for this application is characterized by an impeller diameter of about $40 \mathrm{~mm}$ is. In Figure 3 total-to-total pressure ratio and total-to-total efficiency vs. corrected mass flow rate are reported referring to different levels of compressor corrected rotational speed.

Compressor maps reported are referred to the following parameters:

259

$$
\text { - Reduced rotational speed: } \quad[\mathrm{rpm}]
$$

$$
n_{c r}=\frac{n \cdot \sqrt{T_{0}}}{\sqrt{T_{T 1}}}
$$

262

$$
\beta_{T T}=\frac{p_{T 2}}{p_{T 1}}
$$

$$
M_{c r}=\frac{M_{c} \cdot p_{0} \cdot \sqrt{T_{T 1}}}{p_{T 1} \cdot \sqrt{T_{0}}}
$$


where: $\quad \mathrm{T}_{0}=293.15 \mathrm{~K}$

$$
\eta_{c T T}=\frac{T_{T 2 s}-T_{T 1}}{T_{T 2}-T_{T 1}}
$$

The compressor performance curves are measured from the choking zone to the surge line changing the external circuit characteristic through a motorized throttle valve located downstream of the compressor (Figure 1). The surge condition is identified recording the downstream instantaneous pressure signal to detect the surge frequency through a Fast Fourier Analysis [30].



Fig. 3: Measured compressor steady flow map.

Engine simulation activities described in this paper have been developed referring to the above reported turbines and compressor maps. Simulations are performed referring to ICE "fixed point" and "multiple points" strategies, taking into account different turbocharger configurations (see Table 1), as better explained in the "ICE modelling and simulation" section. In particular, to satisfy massflow rates and boost pressure required by the simulated ICE, the similitude scaling approach has been applied to reproduce the appropriate characteristic curve.

Both turbines were coupled to the same compressor, scaled in similitude with respect to the tested machine (Figure 3), adopting a mass flow multiplier of 0.75 . At the same level of compressor pressure ratio and thermodynamic inlet conditions, the same efficiency value was assumed, neglecting a possible slight increase of boundary layer losses due to the lower compressor size. A third turbine map (called $C$, in Table 1 ) was also considered scaling the turbine A map in similitude, 
adopting a mass flow upscaling of 1.6. Also in this case, the efficiency was maintained unchanged, even if turbine efficiency gradually improves with size.

\begin{tabular}{|c|c|c|}
\hline Model name & Compressor & Turbine \\
\hline $\begin{array}{c}\text { Reference TC } \\
\text { (fixed point investigation) }\end{array}$ & massflow scaling 0.75 & $\mathrm{~A}$ \\
\hline $\begin{array}{c}\text { ETC } \\
\text { (fixed point investigation) }\end{array}$ & massflow scaling 0.75 & $\mathrm{~A}$ \\
\hline $\begin{array}{c}\text { Baseline engine } \\
\text { (multiple points investigation) }\end{array}$ & massflow scaling 0.75 & $\mathrm{~B}$ \\
\hline $\begin{array}{c}\text { ETC-ICE } \\
\text { (multiple points investigation) }\end{array}$ & massflow scaling 0.75 & $\mathrm{C}$ (massflow scaling 1.6 - Turbine A) \\
\hline
\end{tabular}

Tab. 1: TC Specifications.

\section{ICE modelling and simulation}

A twin-cylinder, 0.9 litre, PFI turbocharged SI engine is modelled using AVL Boost ${ }^{\circledR}$ code. The ICE specifications are listed in Table 2.

\begin{tabular}{|l|l|}
\hline Displacement volume & $894 \mathrm{~cm}^{3}$ \\
\hline Stroke & $84.6 \mathrm{~mm}$ \\
\hline Bore & $82.0 \mathrm{~mm}$ \\
\hline Connecting Rod lenght & $154.0 \mathrm{~mm}$ \\
\hline Compression ratio & 8.5 \\
\hline
\end{tabular}

Tab. 2: ICE Specifications.

Geometrical and functional ICE characteristics come from a validated and verified Boost model [34]. Valve flows, injector specifications, pipe sizes, element temperatures and friction features result from manufacturer data and Boost library.

The model includes an air cleaner, a turbocharger and an air cooler in the intake system. The throttle is replaced by a restriction in the intake plenum inlet pipe. The exhaust system consists of a "simplified square cell catalyst" and three different volumes, besides the turbine. Inlet and outlet boundaries are set at normal ambient pressure.

Fuel injection system includes two injectors located in the intake ducts just upstream of the intake valves. Gasoline injection is continuous and set to get the required ratio with respect to the air mass-flow measured at Measuring Point 1 (shown in Figure 4).

Vibe combustion heat release and Woschni 1978 Heat Transfer models [35] are employed. Perfect mixing model is selected for the scavenging process.

The most important modification to the original $\mathrm{AVL}$ model is the replacement of the turbocharger "simplified model" with the "full model". In the simplified model the turbocharger simulation is performed using the "waste gate calculation" mode, which means that the waste-gate mass flow 
rate is calculated from the target pressure ratio across the compressor, the turbocharger efficiency and the turbine size, while compressor and turbine maps are not needed. The full model gives a more detailed description of turbocharger behaviour and requires the implementation of both compressor and turbine maps.

Simulations are performed referring to ICE fixed point and multiple points strategies taking into account different turbocharger configurations, as reported in Tab.1. The ICE fixed point strategy is typical of a range extender configuration, while the multiple points is correlated to a standard vehicle application.

Both ICE models are developed in Boost environment: one refers to a classical turbocharger configuration with waste-gate valve while the other considers the use of an ETC consisting of an electric drive connected to the shaft of a fixed-geometry TC without waste-gate valve. This type of ETC is modelled in the Boost code by coupling the turbocharger to an electric machine, which is represented by a specific module (Figure 4) characterized by an efficiency level of $100 \%$ since its electrical losses are included in the detailed vehicle model.

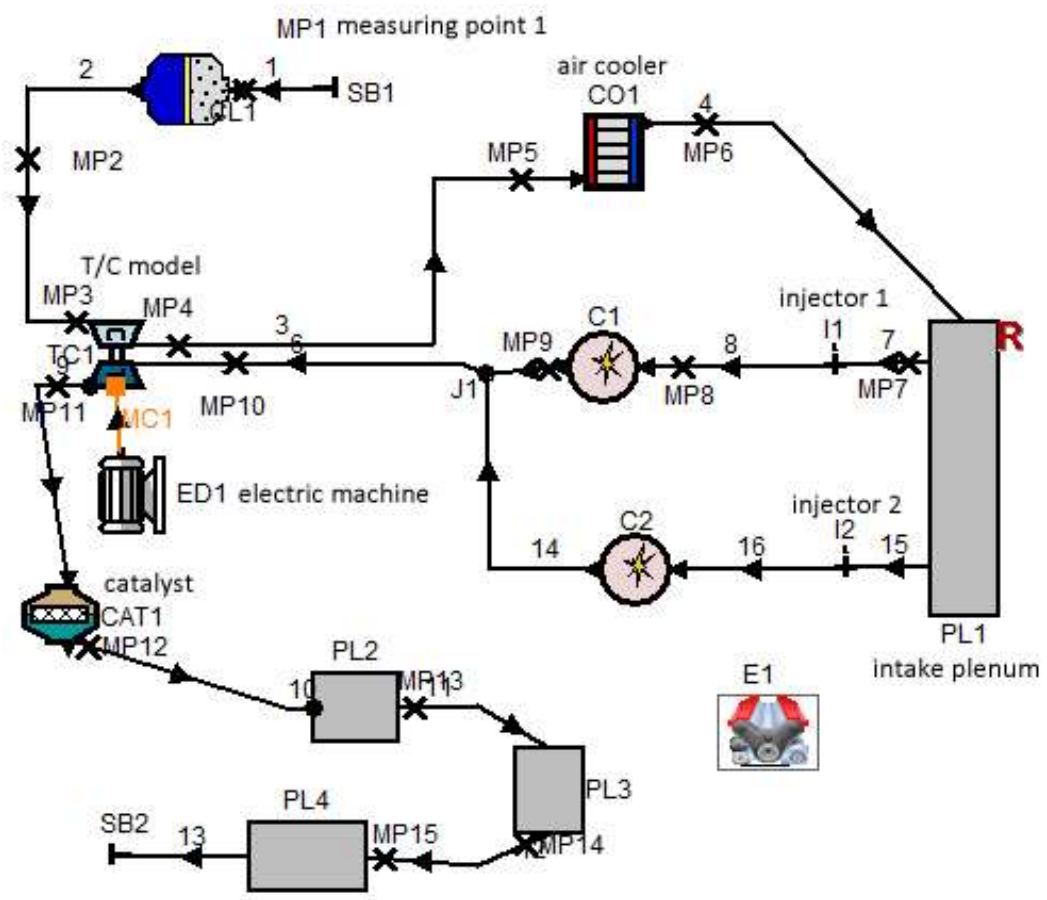

Fig. 4: ICE Boost model, Electric Turbo Compound version.

\subsection{Fixed point simulation results}

Preliminary simulations are conducted at a fixed ICE operating condition (as in the case of rangeextended vehicles) as reported in Table 3. Starting from $1500 \mathrm{rpm}, 1.53$ bar absolute boost pressure and 14.5 A/F ratio, reference TC and ETC are compared. In the case of "reference TC", turbine A is properly sized to supply only the power necessary for the compressor. For "ETC" simulation a turbine able to furnish more power is selected (turbine B in Tab.1), therefore the extra power provided is collected by the electric machine. However, in the absence of ETC, a waste gate strategy must be applied with turbine B (case "reference sim" in Table 3). 
Other points at higher ICE rpm are simulated both for "reference TC" and "ETC" with turbine B, as shown in Table 3. At $1500 \mathrm{rpm}$ the best overall efficiency is obtained with the ETC generating 0.28 $\mathrm{kW}$ of electrical power. However, with respect to the reference TC, ICE efficiency is affected by increased exhaust backpressure, thus the reduction of total specific fuel consumption turns out to be unsubstantial (only $1 \%$, without considering electrical losses).

At $2000 \mathrm{rpm}$ and 1.65 bar, corresponding to the best ICE efficiency with reference TC, ETC provides a slight improvement, less than $2 \%$, in terms of total BSFC. Increasing the rotational speed, 3000 and $4000 \mathrm{rpm}$, ETC effect becomes negative due to the exhaust backpressure raised to unacceptable level, suggesting the adoption of a turbine with increased swallowing capacity for this application.

\begin{tabular}{|c|c|c|c|c|c|c|c|c|c|c|}
\hline & \begin{tabular}{|c|}
$\begin{array}{c}\text { WG } \\
\text { bypass }\end{array}$ \\
\end{tabular} & $\begin{array}{c}\text { Rot. } \\
\text { speed }\end{array}$ & $\begin{array}{l}\text { Boost } \\
\text { press. }\end{array}$ & $\begin{array}{c}\text { Air } \\
\text { massflow }\end{array}$ & $\begin{array}{c}\text { ICE } \\
\text { power }\end{array}$ & $\begin{array}{c}\text { ETC } \\
\text { power }\end{array}$ & ICE BSFC & Tot BSFC & $\begin{array}{c}\text { Exhaust } \\
\text { backpressure }\end{array}$ & Turbine \\
\hline & $\%$ & rpm & bar & $\mathrm{kg} / \mathrm{s}$ & $\mathrm{kW}$ & $\mathrm{kW}$ & $\mathrm{g} / \mathrm{kWh}$ & $\mathrm{g} / \mathrm{kWh}$ & bar & \\
\hline $\begin{array}{l}\text { Reference } \\
\text { TC }\end{array}$ & 0 & 1500 & 1.53 & 0.0170 & 17.00 & - & 248.37 & 248.37 & 1.21 & (A) \\
\hline $\begin{array}{l}\text { Reference } \\
\text { sim }\end{array}$ & 15 & 1500 & 1.53 & 0.0170 & 16.90 & - & 248.99 & 248.99 & 1.26 & (B) \\
\hline ETC & 0 & 1500 & 1.53 & 0.0170 & 16.90 & 0.28 & 250.59 & 246.51 & 1.31 & (B) \\
\hline $\begin{array}{l}\text { Reference } \\
\text { TC }\end{array}$ & 22 & 2000 & 1.65 & 0.0247 & 24.78 & - & 248.07 & 248.07 & 1.41 & (B) \\
\hline ETC & 0 & 2000 & 1.65 & 0.0246 & 24.30 & 0.80 & 251.62 & 243.60 & 1.53 & (B) \\
\hline $\begin{array}{l}\text { Reference } \\
\text { TC }\end{array}$ & 40 & 3000 & 1.64 & 0.0382 & 37.41 & - & 253.73 & 253.73 & 1.53 & (B) \\
\hline ETC & 0 & 3000 & 1.65 & 0.0385 & 35.10 & 2.25 & 275.00 & 258.43 & 1.94 & (B) \\
\hline $\begin{array}{l}\text { Reference } \\
\text { TC }\end{array}$ & 47 & 4000 & 1.64 & 0.0507 & 47.44 & - & 266.07 & 266.07 & 1.66 & (B) \\
\hline ETC & 0 & 4000 & 1.65 & 0.0510 & 41.98 & 3.51 & 301.00 & 277.77 & 2.32 & (B) \\
\hline
\end{tabular}

Tab. 3: Comparison for engines operating at fixed point

\subsection{Multiple points simulation results}

ICE behaviour in standard vehicle application is simulated referring to a classical turbocharger configuration with waste-gate valve and then compared to the same engine equipped with an ETC.

Baseline cases for 24 different operating conditions are considered and reported in Table 4 . Corresponding Brake Specific Fuel Consumption (BSFC) results are shown in map of Figure 5.

Simulations at the same operating conditions of the ICE fitted with ETC are reported in Table 5. The simulated steady points are similar, with the exception of full load 800 and $1500 \mathrm{rpm}$ : at low speeds and full load ETC system is used to achieve higher power levels. 


\begin{tabular}{|c|c|c|c|c|c|c|c|}
\hline load & \multicolumn{6}{|c|}{ ICE speed (rpm) @ intake manifold pressure (bar) } & Turbine \\
\hline $100 \%$ & $800 @ 1.31$ & $1500 @ 1.53$ & $2000 @ 1.65$ & $2500 @ 1.65$ & $3000 @ 1.64$ & $4000 @ 1.63$ & (A) \\
\hline ca. $80 \%$ & $800 @ 1.17$ & $1500 @ 1.30$ & $2000 @ 1.30$ & $2500 @ 1.29$ & $3000 @ 1.30$ & $4000 @ 1.29$ & (A) \\
\hline ca. $60 \%$ & $800 @ 1.00$ & $1500 @ 1.00$ & $2000 @ 1.00$ & $2500 @ 1.00$ & $3000 @ 1.00$ & $4000 @ 1.00$ & (A) \\
\hline $\begin{array}{l}\text { ca. } 25 \% \\
\text { (throttled) }\end{array}$ & $800 @ 0.61$ & $1500 @ 0.60$ & $2000 @ 0.60$ & $2500 @ 0.61$ & $3000 @ 0.60$ & $4000 @ 0.59$ & (A) \\
\hline
\end{tabular}

Tab. 4: baseline simulated cases.

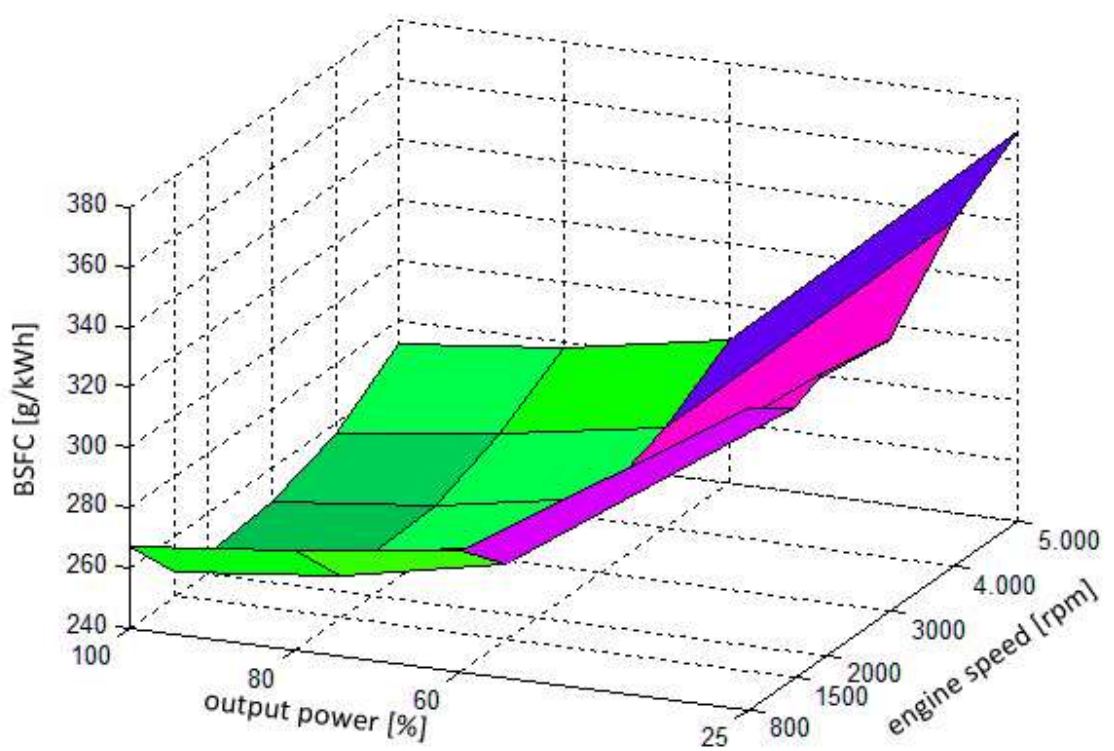

Fig. 5: Baseline BSFC Map

The turbocharger turbine $(C)$ is characterized by a larger size ( $+60 \%$ swallowing capacity scaling, in similitude) than in the baseline case in order to limit the backpressure at ICE high speeds and loads, despite the absence of waste-gate valve. Therefore, at low ICE rotational speed levels the fixed geometry turbine cannot give enough energy to drive the compressor, energy which is supplied by the electric device.

\begin{tabular}{|c|c|c|c|c|c|c|c|c|}
\hline Ioad & \multicolumn{7}{|c|}{ ICE speed (rpm) @ intake manifold pressure (bar) } & Turbine \\
\hline $100 \%$ & $800 @ 1.41$ & $1500 @ 1.65$ & $2000 @ 1.65$ & $2500 @ 1.66$ & $3000 @ 1.66$ & $4000 @ 1.65$ & (C) \\
\hline ca. $80 \%$ & $800 @ 1.19$ & $1500 @ 1.30$ & $2000 @ 1.30$ & $2500 @ 1.30$ & $3000 @ 1.31$ & $4000 @ 1.30$ & (C) \\
\hline ca. $60 \%$ & $800 @ 1.00$ & $1500 @ 1.00$ & $2000 @ 1.00$ & $2500 @ 1.00$ & $3000 @ 1.00$ & $4000 @ 1.00$ & $(\mathrm{C})$ \\
\hline $\begin{array}{c}\text { ca. } 25 \% \\
\text { throttled) }\end{array}$ & $800 @ 0.61$ & $1500 @ 0.61$ & $2000 @ 0.59$ & $2500 @ 0.61$ & $3000 @ 0.61$ & $4000 @ 0.60$ & (C) \\
\hline
\end{tabular}

Tab. 5: ETC-ICE simulated cases. 
To compare the baseline case with the ETC-fitted ICE, total power, evaluated as the sum of the engine power and the electrical power with 100\% electric drive efficiency, is plotted in Figure 6 versus rotational speed. As it can be observed, a slight improvement of total power occurs at midlow ICE rotational speed levels and increases with ICE speed, due to the larger exhaust gas massflow rate providing, on the TC group, an extra power recovered by the electrical machine.

393
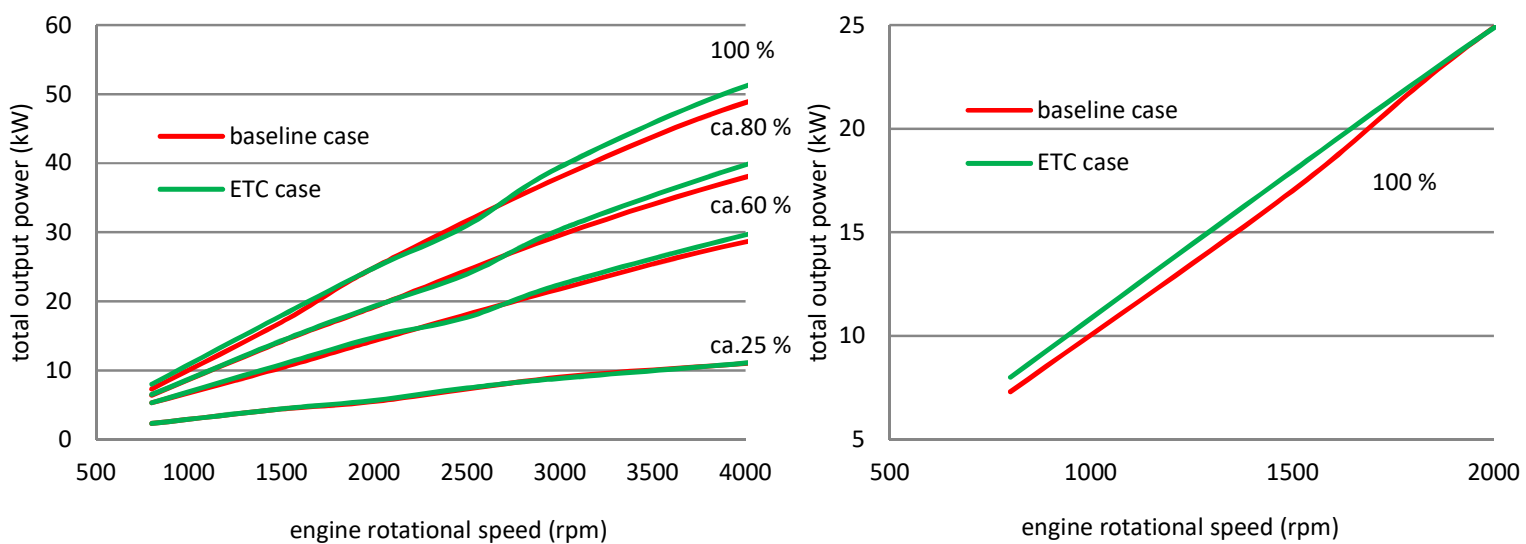

Fig. 6: Total output power - comparison between baseline and ETC-ICE, at full power, ca. $80 \% \mathrm{ca} .60 \%$, ca. $25 \%$. Focus on full load, low rpm.

At ICE full load condition (Figure 7), the electric drive acts as motor below $2500 \mathrm{rpm}$ assisting the turbocharger to achieve the required boost pressure. Over $2500 \mathrm{rpm}$, the electric drive works as generator 'braking' the turbocharger and collecting the energy surplus provided by the turbine. In the cases of ca. $80 \%$ and ca. $60 \%$ of full load, the electric drive is always keeping energy from the turbocharger. Below ca.60\% of full load (Figure 7) the ECU (Engine Control Unit) switches from boost pressure control to classical intake throttling. In these conditions the amount of exhaust gas energy rapidly falls down and the ETC recovers only small amounts of energy, with no influence on total specific fuel consumption (which takes total power into account).
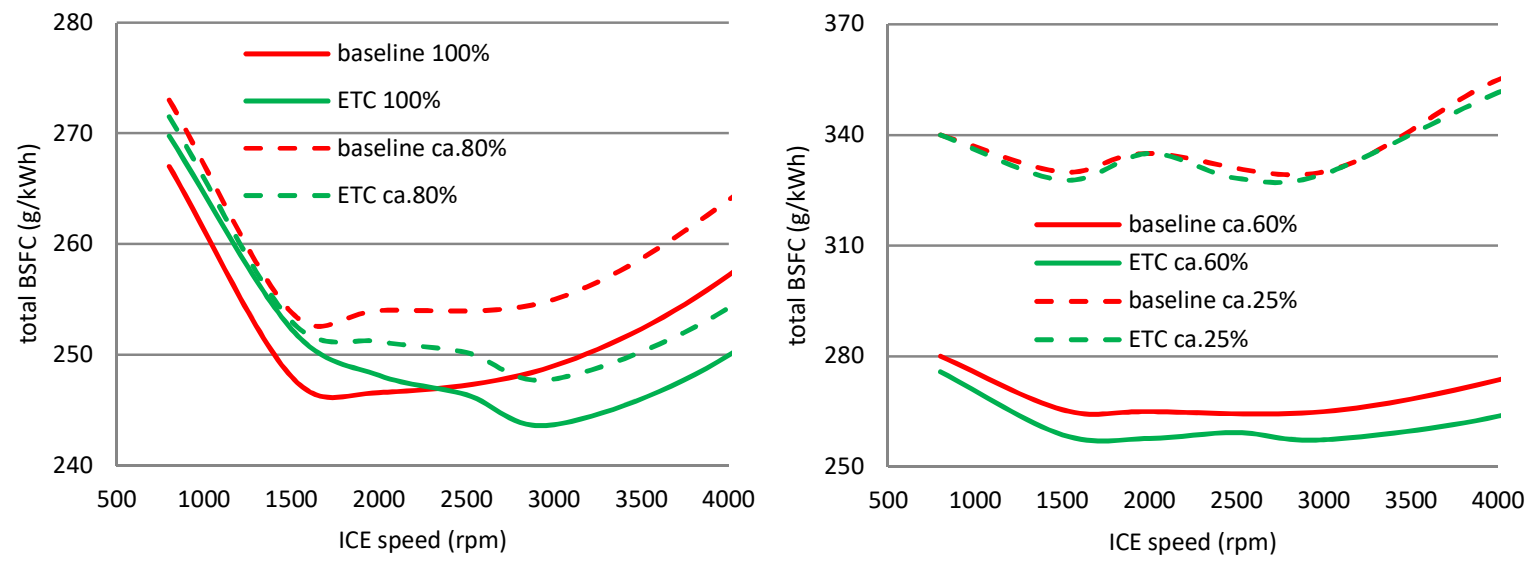

Fig. 7: Total Brake Specific Fuel Consumption - comparison between baseline and ETC-ICE at various loads. 
In Figure 8 the baseline BSFC is compared with the total BSFC of the ETC-fitted ICE at same operating conditions. In forced induction conditions (above ca.60\% of full load) moderate reductions of fuel consumption occur at every ICE rotational speed level. Only at ICE rotational speeds below $2000 \mathrm{rpm}$ at full load, a slight increase arises due to electric power spent to achieve the boost pressure target. On the other hand the boost pressure reached is higher than in the baseline case, with obvious advantage in terms of power output. In naturally aspirated conditions (below ca.60\% of full load), only negligible BSFC improvements occur.

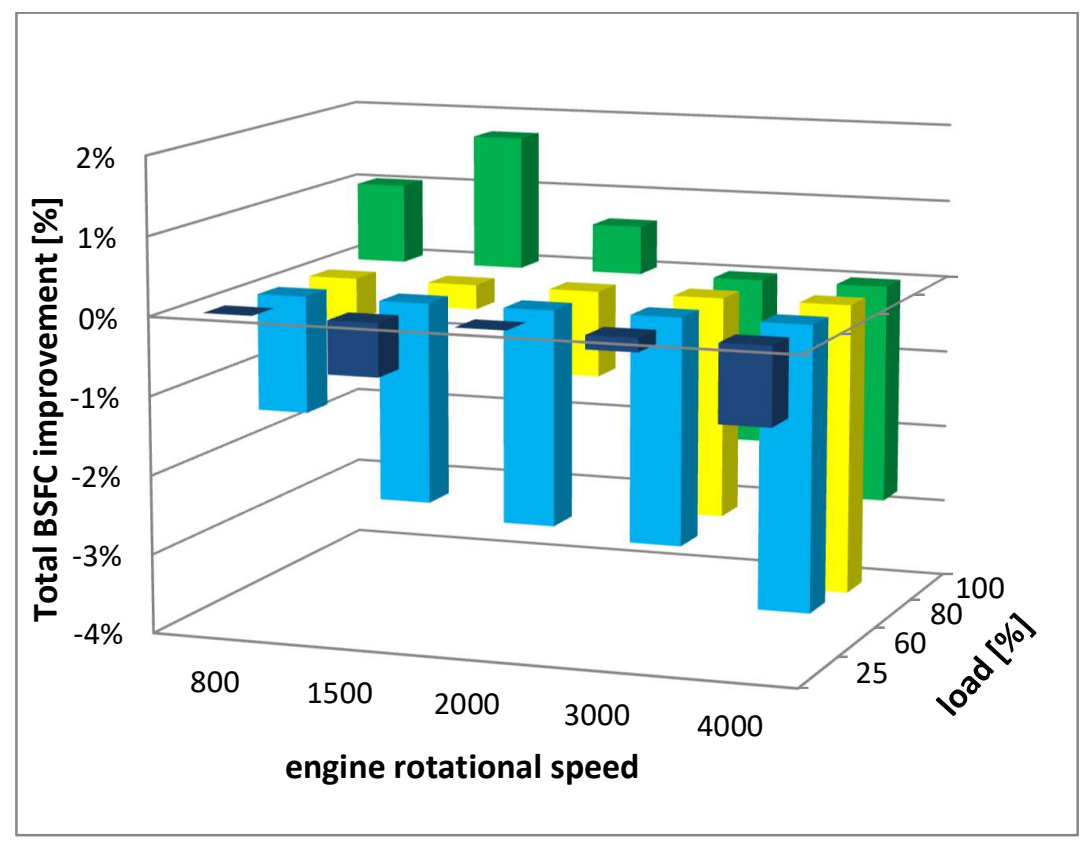

Fig. 8: Percentage variation of total Brake Specific Fuel Consumption - comparison between baseline and ETC-ICE at various loads.

\section{Powertrain architecture}

The activity, initially focused on the ICE and the TC group, moves to the whole powertrain modelling, to verify the effectiveness of the proposed solution.

As in the solution currently in use in the F1 Championship, the ETC system can be used in an hybrid powertrain [36,37]. However, as first approach, the powertrain architecture has been maintained, as far as possible, the same of a conventional vehicle equipped with a standard TC group. The conventional electrical system is kept unchanged, apart from the introduction of the ETC system. A sketch is shown in Figure 9.

The electrical machine of the ETC system to convert the excess of exhaust energy into electricity is directly coupled to the shaft of the standard TC group. On the other hand, The alternator is coupled to the ICE and interfaced with the DC network through a rectifier bridge, to feed the auxiliary loads. The conventional alternator, the rectifier bridge, the SLI battery and the electrical auxiliary loads are kept unchanged.

It must however be mentioned that the rectifier bridge could be replaced with a bidirectional converter, to allow the electricity produced by the ETC to be converted back into mechanical 
energy at the alternator pulley. This option could be considered when the electrical energy generated by the ETC is so large that, in the case of low energy consumption by the auxiliary loads, the standard SLI battery is inadequate to store it all. On the contrary, for small amounts of generated energy, the cheaper diode rectifier bridge is sufficient, and the SLI energy is totally stored inside the battery. We adopt the diode bridge solution, because simulations show that in our case the available ETC electrical energy can always be effectively stored in the battery.

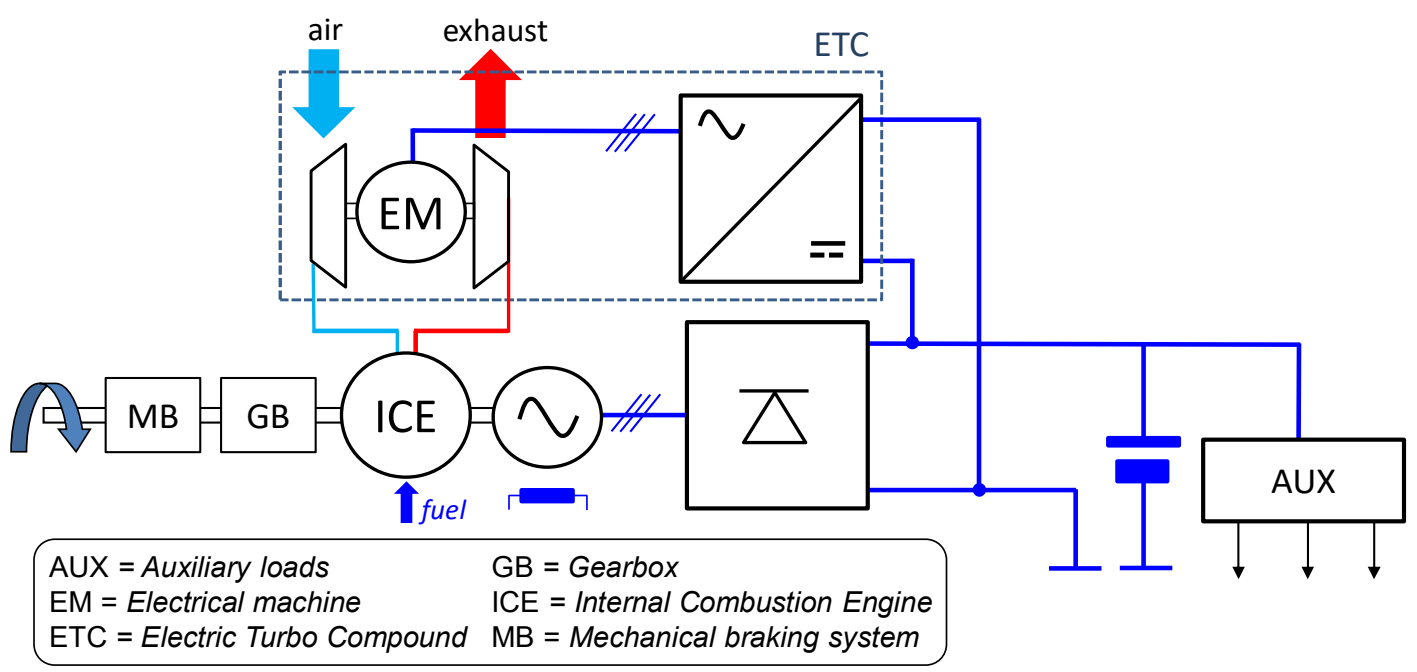

Fig. 9: Powertrain Architecture

\section{Powertrain modelling and simulation}

The modelling of the selected architecture is performed by means of a suitable powertrain simulation model, built for carrying out fuel consumption analysis. The model is of the forward type, since the vehicle trip is determined as a consequence of driver commands.

The model is conceived using 3DS's Dymola [38], based on Modelica language [39]. In addition to the conventional powertrain, it includes the electric turbo compound (ETC). The results obtained with the model for the vehicle equipped with the ETC system are compared with those relative to the conventional version, mainly to evaluate energy flows and fuel consumption.

\subsection{The simulation model}

The different subsystems are modelled weighting accuracy and complexity for the considered purpose. In particular, since the fastest transients in the powertrain model show time constants in the order of $100 \mathrm{~ms}$, much faster phenomena such as combustion dynamics or valve switching inside electronic converters are considered to be algebraic.

Hereinafter, a brief description of the main model subsystems is presented. 
The internal combustion engine (ICE) model evaluates the fuel consumption and torque as an algebraic function of engine speed and throttle position; the generated torque is applied to a submodel simulating the mechanical inertia. The model fuel flow control includes over-run cut off and idle speed control. The fuel consumption and torque values are obtained from the ICE modelling activity previously described, both in the conventional configuration equipped with the standard TC group, and in the other one, equipped with the ETC system. The values differ mainly due to the different ambient conditions at the inlet and exhaust engine ports. In fact, as detailed in the previous paragraph, the waste gate valve is considered only in the standard TC group, while it is removed in the ETC system. The effects, being the fluidic ports not included in the considered model, are indeed directly considered in fuel consumption and torque functions.

The ETC model contains a permanent-magnet synchronous machine (EM) and an electronic converter. Still because the fluidic model of the TC group is not represented in the model, the values of torque and rotary speed given by the ICE modelling activity, which depend on throttle and ICE rotational speed, have been directly imposed to the pulley of the electrical machine. A general representation of the two models is shown in Figure 10. The main electrical machine parameters are shown in Table 6. Some analysis on design and manufacturing aspects is presented in [40].
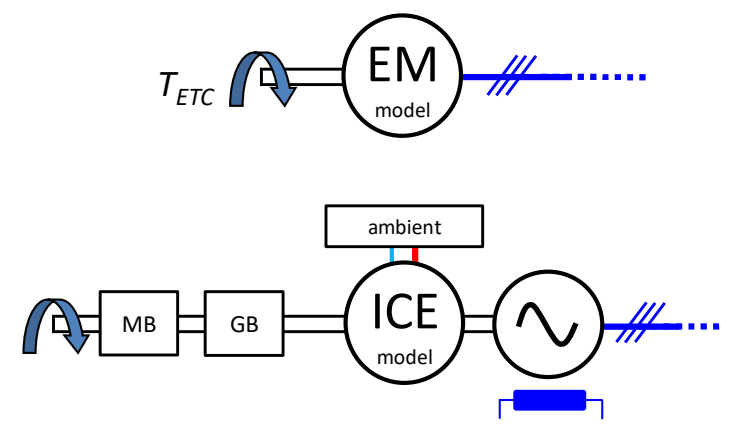

Fig. 10: ETC electrical machine and ICE models

\begin{tabular}{|l|l|}
\hline Nominal power (kW) & 2 \\
\hline Nominal torque (Nm) & 0.5 \\
\hline Nominal speed (rpm) & 40000 \\
\hline Maximum speed (rpm) & 160000 \\
\hline Nominal RMS line voltage (V) & 7.8 \\
\hline Nominal current (A) & 148 \\
\hline Efficiency @ 80000 rpm (\%) & 75 \\
\hline
\end{tabular}

Tab. 6: Model parameters for the ETC electrical machine

As regards the three-phase alternator, the model of a conventional machine is used. Maximum DC current is $140 \mathrm{~A}$, maximum speed is $15000 \mathrm{rpm}$. Alternator and diode bridge losses are taken into account using interpolation formulas; the resulting efficiency is $75 \%$ at $7500 \mathrm{rpm}$. 
The vehicle is modelled through a mechanical equation describing its longitudinal behaviour. Resistance force is modelled as a second-order polynomial, to take into account rolling resistance ad aerodynamic drag. Furthermore, the transmission model is composed by an automatic gearbox including a torque converter with a lock-up clutch. The gearbox is modelled as a series of fixed gear ratios, following the approach shown in [41], that are shifted according to a specific control logic. In particular, the control logic determines the shift point based on throttle position and vehicle speed, according to a predefined shift map. Typical available values for the vehicle under study are employed [42]. To ease the comparison between the standard and the new powertrain configuration, standard gear ratios and control shift strategy are kept unchanged.

\subsection{Energy management strategy}

The main purpose of the energy management strategy is, besides interpreting the driver requests and feeding the electrical auxiliary loads, to manage the electrical energy, in order to allow the battery to receive the excess power generated by the ETC with respect to the amount needed by the auxiliary loads. Therefore, the power management module (PMM) has the fundamental roles to:

- interpret the driver brake/accelerator commands and convert them in terms of torque request;

- keep the battery voltage at a level close to that of conventional cars, since the standard electrical system is unchanged;

- guarantee a battery SOC that makes the battery capable to accept all the available regenerative braking energy. In fact, nevertheless the problem mainly involves hybrid and electric vehicles, some modest energy recovery can be ensured also in conventional ones. A comprehensive description of the problem is shown also in $[43,44]$.

A schematic implementation of the described roles is shown in Figure 11. The driver model is a Proportional-Integral controller with some additional elements to better model the actual driver behaviour. In fact, the PI determines the torque request based on the error between actual and wished speed, and torque request is split into two signals corresponding to the accelerator and brake pedal positions. Therefore, the driver only controls one pedal at a time and does not jump rapidly from the throttle to the brake pedal. The driver model parameters, that already represent an average driver behaviour, are maintained at their defaults.

The accelerator request goes directly to an electronic control unit (ECU), which regulates the fuel and the air flows. On the other hand, the brake request signal needs to be further split into regenerative and dissipative braking components. When the torque request is slightly negative, i.e. the brake pedal is slightly pushed, this torque is only obtained by means of an increase of the alternator load that produces electrical braking and the mechanical brakes are not activated: this is obtained by means of the dead-band non-linear block in the signal path that generates $T_{M B}$.

Sole electrical braking is kept as far as the maximum torque of the alternator is achieved (see the saturation block shown in Figure 11), or the battery is fully charged. When stronger braking is needed, mechanical braking must be added. This occurs when the brake request signal is higher than the dead-band zone of the block feeding $T_{M B}$.

To accomplish the other PMM role, i.e. to keep the battery voltage close to the usual level of conventional cars, and to ensure a SOC that allows the battery to accept the braking energy, the 
DC voltage reference is maintained slightly below $14 \mathrm{~V}$. This is implemented through a PI controller (the PI block shown in Figure 11), having the battery SOC reference (SOC ${ }^{*}$ ) around 0.9 .

The torque reference $T_{\mathrm{ED}}$, composed by the output of the $\mathrm{PI}$ controller and the additional term due the regenerative braking, acts directly on the electronic control unit (ECU) of the electrical machine. The ECU, taking into account the alternator rotary speed $(\Omega)$, determines the requested excitation current $l_{\text {ecc. }}$.



Fig. 11: Energy management strategy

\subsection{Powertrain simulation results}

The simulations are performed considering three driving cycles and two different vehicle configurations, to properly analyse the ETC system under different working conditions. The three driving cycles, all from CADC (Common Artemis Driving Cycle), are described in Table 7 and shown in Figure 12. These cycles, differently from other standard cycles as NEDC (New European Driving Cycle) considered in [40], are able to represent the vehicle usage in urban, extra-urban roads and motorways in a realistic way. Further details about CADC are shown in [45]. 


\begin{tabular}{|l|l|l|l|}
\hline & Urban & Rural Road & Motorway \\
\hline Duration $(\mathrm{s})$ & 920 & 1081 & 1067 \\
\hline Distance $(\mathrm{km})$ & 4.5 & 17.3 & 29.6 \\
\hline Average speed $(\mathrm{km} / \mathrm{h})$ & 17.5 & 57.5 & 99.7 \\
\hline Maximum speed $(\mathrm{km} / \mathrm{h})$ & 58 & 112 & 150 \\
\hline Speed distribution $(\%)$ & & & \\
Idle & 29 & 3 & 2 \\
Low speed $(0<v<50)$ & 69 & 31 & 15 \\
Medium speed $(50<v<90)$ & 2 & 59 & 13 \\
High speed $(v>90)$ & 0 & 7 & 70 \\
\hline
\end{tabular}

Tab. 7: Characteristics of CADCs (Common Artemis Driving Cycles)
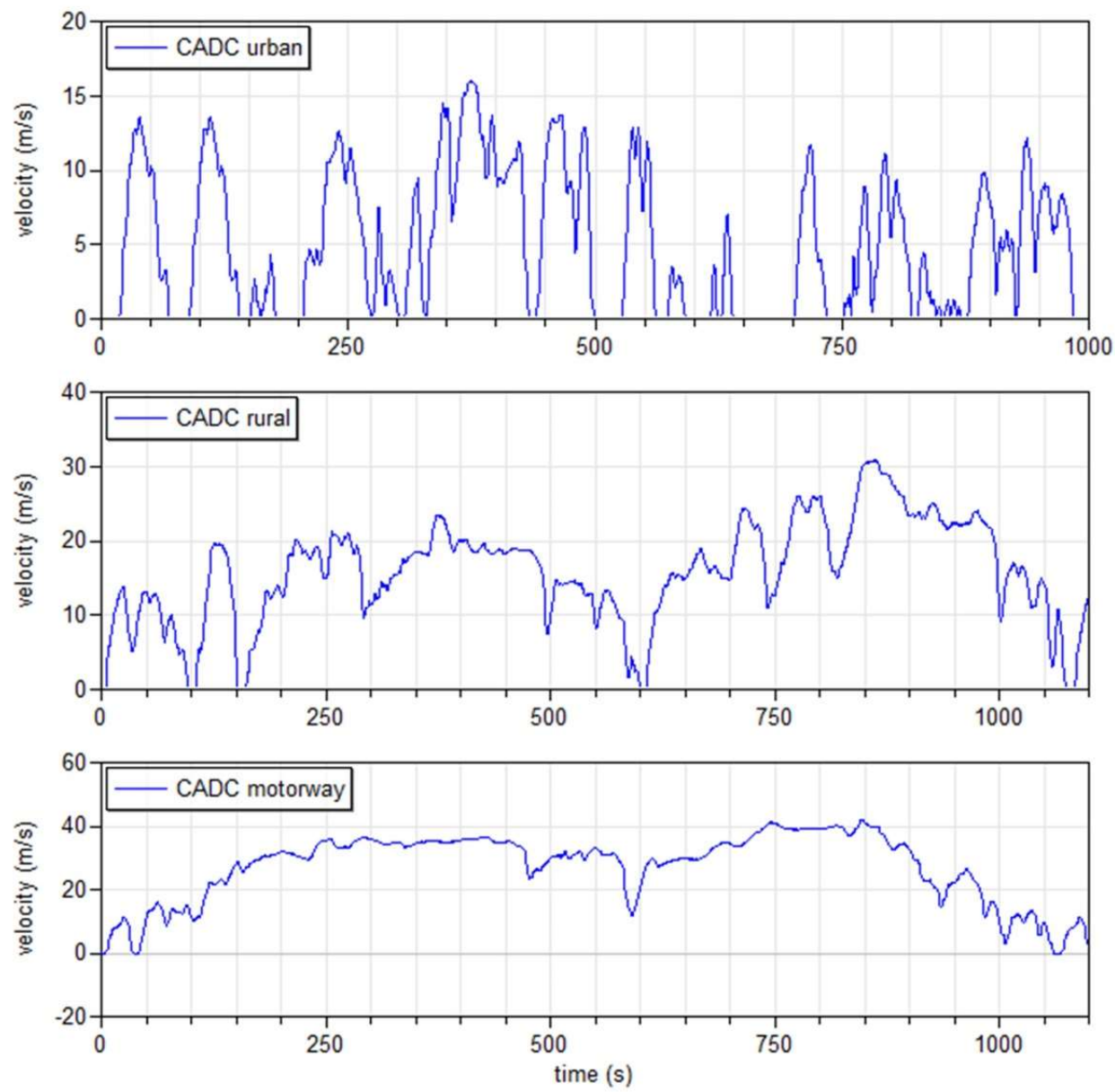

Fig. 12: CADC (Common Artemis Driving Cycle) urban, rural, motorway

Two different vehicle configurations are considered: the first one $\overline{\bar{y}}_{\overline{\mathbf{m}}}$ representative of a small medium car, the second one typical of a top medium car. The details are shown in Table 8. Regarding the electrical auxiliary loads, from analysis of literature [46] an average value of $350 \mathrm{~W}$ is considered. 


\begin{tabular}{|l|l|l|}
\hline \multirow{4}{*}{ Small medium } & Mass $(\mathrm{kg})$ & 1200 \\
\cline { 2 - 3 } & Frontal area $\left(\mathrm{m}^{2}\right)$ & 1.8 \\
\cline { 2 - 3 } & Cx & 0.31 \\
\hline \multirow{4}{*}{ Top medium } & Mass $(\mathrm{kg})$ & 1700 \\
\cline { 2 - 3 } & Frontal area $\left(\mathrm{m}^{2}\right)$ & 2.0 \\
\cline { 2 - 3 } & Cx & 0.28 \\
\hline
\end{tabular}

Tab 8: Vehicle model parameters

Figure 13 shows mechanical power and rotary speed of the ETC electrical machine, during a portion of the CADC rural. It shows that during the ICE acceleration transients almost at full load, the ETC works as generator producing electrical energy (i.e. the mechanical power assumes negative values), while during braking or at idle speed it works as motor (i.e. the mechanical power is positive), keeping the turbocharger unit at the desired speed by compensating the energy losses.
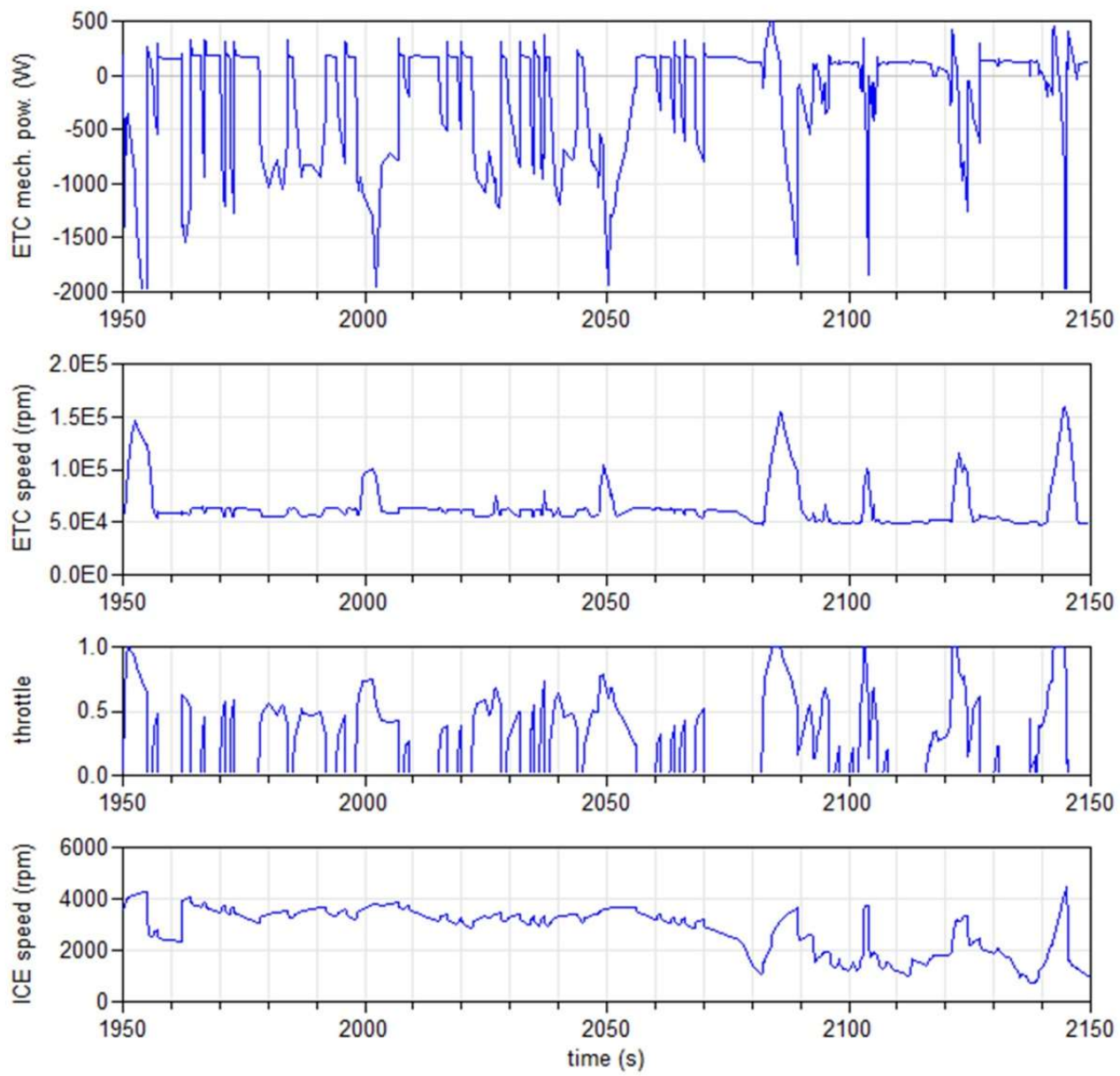

Fig. 13: ETC mechanical power and rotary speed, ICE throttle, ICE rotary speed, top medium car, portion of CADC rural

Figure 14 shows the generated DC electrical power. During acceleration and drive at constant 
additional term in the control logic previously described, the generated electric power rises up. However, according to the control logic adopted, the battery SOC (state of charge) remains under control.
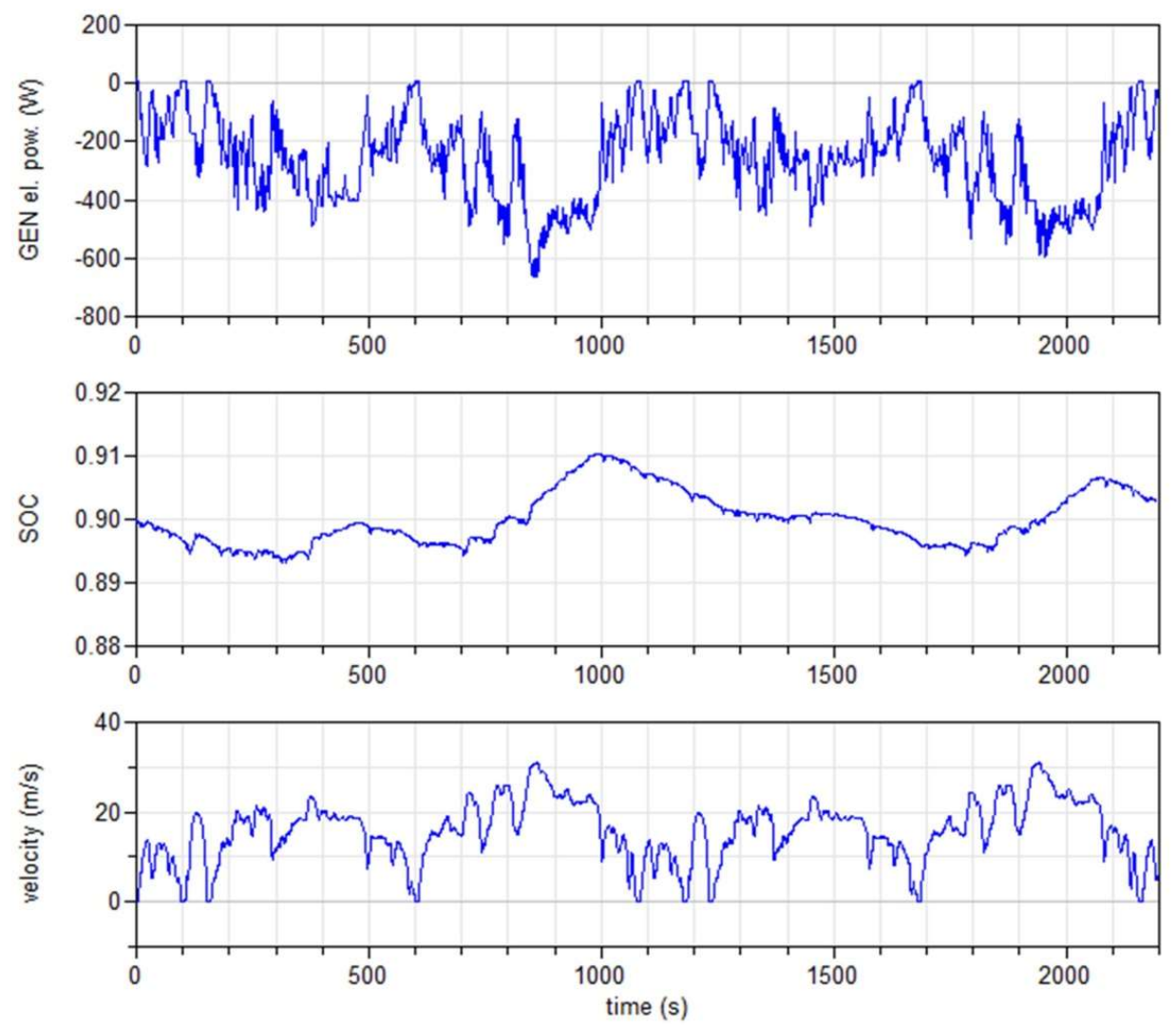

Fig. 14: Generator DC electrical power, battery SOC, top medium car, CADC rural (two cycles represented)

Finally, the fuel consumption results are related to the examined two vehicle configurations, performing the three considered CADC cycles (i.e. urban, rural and motorway). Simulation have been firstly performed for the standard TC group configuration, then considering the ETC system. Results are shown in Table 9. Variation refers to the percentage difference, in terms of coverage distance per litre, of the vehicle equipped with the ETC system in comparison with the baseline TC configuration.

\begin{tabular}{|c|l|l|l|l|}
\hline Vehicle & \multicolumn{1}{|c|}{ Cycle } & \multicolumn{1}{|c|}{$\begin{array}{c}\text { Baseline TC } \\
(\mathbf{k m} / \mathbf{L})\end{array}$} & $\begin{array}{c}\text { ETC system } \\
(\mathbf{k m} / \mathbf{L})\end{array}$ & $\begin{array}{c}\text { Variation } \\
(\mathbf{\%})\end{array}$ \\
\hline \multirow{4}{*}{ Small medium } & CADC urban & 7.7 & 7.5 & -1.9 \\
\cline { 2 - 5 } & CADC rural & 14.6 & 14.5 & -0.5 \\
\cline { 2 - 5 } & CADC motorway & 18.1 & 18.4 & +1.7 \\
\hline \multirow{3}{*}{ Top medium } & CADC urban & 6.9 & 6.8 & -0.9 \\
\cline { 2 - 5 } & CADC rural & 13.4 & 13.6 & +1.5 \\
\cline { 2 - 5 } & CADC motorway & 17.0 & 17.5 & +2.7 \\
\hline
\end{tabular}


The table shows that, the ETC does not improve fuel economy of the smaller vehicle, especially when employed in urban cycles. As a matter of fact, even though the ETC sometimes delivers small amounts of electrical energy, most of the time it requires electrical power to maintain the TC group at the desired boost pressure. In this case, fuel consumptions may even rise up, in comparison with the baseline TC solution.

The ETC is much more advantageous in the case of the larger vehicle, particularly when extraurban roads or motorways are considered. In fact, under these conditions, engine works mainly in the high loads and rpm region and consequently the ETC delivers significantly larger electrical power that causes an improvement of fuel consumption of around $2.7 \%$.

It must however be noticed that the fuel savings shown in Table 9 are significantly smaller than the value of $4 \%$ obtained in the steady state analysis. This is a consequence not only of the fact that during road cycle simulations the operating points of ICE, turbine and compressor vary continuously (and often they are low-efficiency points), but also of the fact that in the steady state analysis the electrical components (alternator, converter, battery) are considered lossless, while in the driving-cycle simulations their losses are taken into account.

\section{Summary/Conclusions}

The paper relates to a numerical research carried out in cooperation between the Universities of Pisa and Genoa and focused on the evaluation of the benefits resulting from the application of an Electric Turbo Compound (ETC) to a small twin-cylinder SI engine intended for cars with conventional architecture (not hybrid).

Starting from the experimental maps of two turbines and one compressor, the complete model of a turbocharged engine is created using the AVL BOOST one-dimension code. Simulations are performed referring to ICE fixed point and multiple points strategies taking into account different turbocharger configurations. The numerical activity then moves to the whole vehicle/powertrain modelling, considering three driving cycles and two different vehicle configurations, adopting the 3DS's Dymola code based on Modelica language.

When the engine is run at a fixed point (characteristic of a range extender), an electric drive applied to a conventionally optimized TC group leads to unsubstantial reduction of total specific fuel consumption, since ICE efficiency is affected by increased exhaust backpressure.

As regards the engine operating at various speeds and loads (i.e. in standard vehicle application) and adopting proper turbine sizing, application of ETC is able to produce a moderate efficiency improvements, up to $4 \%$ of total brake specific fuel consumption, depending on engine speed and load. However, ETC leads to benefits as regards boost region extension to the lowest ICE rotational speeds and possible turbo lag reduction.

Concerning the whole vehicle/powertrain simulation, first results confirm that ETC leads to small changes in fuel saving (up to $2.7 \%$ ) in the case of top medium-size cars. Moreover, results show that the ETC does not improve fuel economy of the smaller vehicle, especially when employed in urban cycles when the engine is run in the medium-low load and speed conditions. The ETC is much more advantageous in the case of the larger vehicle, particularly when motorway cycles are considered, since the engine works in the region of high loads and speeds 
Future study will be conducted on other solutions involving ETC, such as its application to compression-ignited ICEs, two-stage turbocharging, turbine and compressor without mechanical link, both with individual electric drive.

\section{References}

[1] Mohd Noor A., Che Puteh R., Rajoo S., "Waste Heat Recovery Technologies In Turbocharged Automotive Engine - A Review", Journal of Modern Science and Technology, Vol.2 No.1, 108119, March 2014.

[2] Saidur R., Rezaei M., Muzammil W.K., Hassan M.H., Paria S., Hasanuzzaman M., "Technologies to recover exhaust heat from internal combustion engines", Renewable and Sustainable Energy Reviews 16, 5649-5659, 2012.

[3] Hountalas D.T., Katsanos C.O., Kouremenos D.A., Rogdakis E.D., "Study of available exhaust gas heat recovery technologies for HD diesel engine applications", Int Journal of Alternative Propulsion 1, 228-49, 2007.

[4] Weerasinghe W.M.S.R., Stobart R.K., Hounsham S.M., "Thermal efficiency improvement in high output diesel engines: a comparison of a Rankine cycle with turbo-compounding", Applied Thermal Engineering 30, 2253-2256, 2010.

[5] Park T., Teng H., Hunter G.L., Van Der Velde B., Klaver J., "A Rankine cycle system for recovering waste heat from HD Diesel Engines - Experimental results", SAE Paper no. 201101-1337; 2011.

[6] Wang T., Zhang Y., Peng Z., Shu G., "A review of researches on thermal exhaust heat recovery with Rankine cycle", Renewable and Sustainable Energy Reviews 15, 2862-2871, 2011.

[7] Sprouse C., Depcik C., "Review of organic Rankine cycles for internal combustion engine exhaust waste heat recovery", Applied Thermal Engineering 51, 711-722, 2013.

[8] Hossain S.N., Bari S., "Waste heat recovery from the exhaust of a diesel generator using Rankine Cycle", Energy Conversion and Management 75, 141-151, 2013.

[9] Tahani M., Javan M., Biglari M., "A comprehensive study on waste heat recovery from internal combustion engines using organic rankine cycle”, Thermal Science, 2013, Vol. 17, No. 2, pp. 611-624.

[10] Tchanche B. F., Lambrinos Gr., Frangoudakis A., Papadakis G.," Low-grade heat conversion into power using organic Rankine cycles - A review of various applications", Renewable and Sustainable Energy Reviews 15, 2011, 3963-3979.

[11] Bass J.C., Kushch A.S., Elsner N.B., "Thermoelectric generator (TEG) on heavy diesel trucks", Proceedings ICT2001. 20 International Conference on Thermoelectrics, Beijing, 2001.

[12] Rowe M. D., "Thermoelectric waste heat recovery as a renewable energy source: Review", Int. J. Innov. Energy Syst. Power 1, 2006,13-23.

[13] Fairbanks J., "Thermoelectric applications in vehicles status 2008”, In: 6th European Conference of Thermoelectrics, Paris, France 2008.

[14] Gou X., Yang S., Xiao H., Ou Q., “A dynamic model for thermoelectric generator applied in waste heat recovery”, Energy 52, 2013, 201-209.

[15] Shuhai Y., Qing D., Hai D., Gequn S., Kui J., "Effect of vehicle driving conditions on the performance of thermoelectric generator" Energy Conversion and Management 96, 2015, 363376.

[16] Zhao R., Zhuge W., Zhang Y., Yin Y., Chen Z., Li Z., "Parametric study of power turbine for diesel engine waste heat recovery", Applied Thermal Engineering 67, 2014, 308-319. 
668

669

670

671

672

673

674

675

676

677

678

679

680

681

682

683

684

685

686

687

688

689

690

691

692

693

694

695

696

697

698

699

700

701

702

703

704

705

706

707

708

709

710

711

712

713

714

715

[17] Callahan T.J., Branyon D.P., Forster A.C., Ross M.G., Simpson D.J., "Effectiveness of Mechanical Turbo Compounding in a Modern Heavy-Duty Diesel Engine", International Journal of Automotive Engineering 3, 69-73, 2012.

[18] Boretti A., "Conversion of a heavy duty truck diesel engine with an innovative power turbine connected to the crankshaft through a continuously variable transmission to operate compression ignition dual fuel diesel-LPG", Fuel Processing Technology 113, 97-108, 2013.

[19] Zhao R., Zhuge W., Zhang Y., Yang M., Botas R. M., Yin Y., "Study of two-stage turbine characteristic and its influence on turbo-compound engine performance", Energy Conversion and Management 95, 2015, 414-423.

[20] Aman M.I., Romagnoli A., Ricardo F., M.-B., "Characterisation of a low pressure turbine for turbocompounding applications in a heavily downsized mild-hybrid gasoline engine", Energy 64, 2014, 3-16.

[21] Cipollone R., Di Battista D., Gualtieri A., "Turbo compound systems to recover energy in ICE", International Journal of Engineering and Innovative Technology (IJEIT) Volume 3, Issue 6, December 2013.

[22] Briggs I., McCullough G., Spence S., Douglas R. "Whole-vehicle modelling of exhaust energy recovery on a diesel-electric hybrid bus", Energy 65, 2014, 172-181.

[23] Katsanos C.O., Hountalas D.T., Zannis T.C., "Simulation of a heavy-duty diesel engine with electrical turbocompounding system using operating charts for turbocharger components and power turbine", Energy Conversion and Management 76, 2013, 712-724.

[24] Newman P., Luard N., Jarvis S., Richardson S., Smith T., Jackson R., Rochette C., Lee D., Criddle M., "Electrical supercharging for future diesel powertrain applications", $11^{\text {th }}$ International Conference on Turbochargers and Turbocharging, The British Museum, London, 2014, Pages 207-216.

[25] Terdich N., Ricardo M.B., "Experimental Efficiency Characterization of an Electrically Assisted Turbocharger", SAE Technical Paper 2013-24-0122, 2013, doi:10.4271/2013-24-0122.

[26] Hopmann U., Algrain M., "Diesel Engine Electric Turbo Compound Technology", SAE Technical Paper 2003-01-2294, 2003, doi:10.4271/2003-01-2294.

[27] Millo F., Mallamo F., Pautasso E., Ganio Mego G., "The Potential of Electric Exhaust Gas Turbocharging for HD Diesel Engines", SAE Technical Paper 2006-01-0437, 2006.

[28] Zhuge W., Huang L., Wei W., Zhang Y. et al., "Optimization of an Electric Turbo Compounding System for Gasoline Engine Exhaust Energy Recovery", SAE Technical Paper 2011-01-0377, 2011

[29] Wei W., Weilin Z., Yangjun Z., Yongsheng H., "Comparative Study on Electric TurboCompounding Systems for Gasoline Engine Exhaust Energy Recovery", ASME Turbo Expo: Power for Land, Sea, and Air, Paper No. GT2010-23204, pp. 531-539, 2010.

[30] Marelli S., Carraro C., Marmorato G., Zamboni G., Capobianco M., "Experimental Analysis on Steady Flow Performance under Unstable Operating Conditions and on Surge Limit of a Turbocharger Compressor", Experimental Thermal and Fluid Science, Volume 53, pages 154160, doi: 10.1016/j.expthermflusci.2013.11.025, February 2014.

[31] Capobianco M., Marelli S., "Waste-gate turbocharging control in automotive SI engines: effect on steady and unsteady turbine performance", SAE Technical paper, Proceedings of the 14th Asia Pacific Automotive Engineering Conference, ISBN: 9780768019544, doi: 10.4271/200701-3543, 2007.

[32] Marelli S., Capobianco M., "Experimental Investigation under Unsteady Flow Conditions on Turbocharger Compressors for Automotive Gasoline Engines", Proceedings of the 10th International Conference on Turbochargers and Turbocharging, p. 219-229, ISBN: 9780857092090, 2012. 
[33] Capobianco M., Marelli S., "Experimental investigation into the pulsating flow performance of a turbocharger turbine in the closed and open waste-gate region", Proceedings of 9th International Conference on Turbochargers and Turbocharging, p. 373-386, ISBN: 9781907599156, doi: 10.1243/17547164C0012010030, 2010.

[34] AVL BOOST v2011.2 Official Examples Library.

[35] Woschni G., "A Universally Applicable Equation for the Instantaneous Heat Transfer Coefficient in Internal Combustion Engines", SAE Paper 6700931

[36] K. Bayindir, M. et alii, "A comprehensive overview of hybrid electric vehicle: Powertrain configurations, powertrain control techniques and electronic control units", Energy Conversion and Management 52 (2011), 1305-1313.

[37] K.T. Chau, Y.S. Wong, "Overview of power management in hybrid electric vehicles", Energy Conversion and Management 43 (2002), 1953-1968.

[38] 3DS Modelon official site: http://www.3ds.com/products/catia/portfolio/dymola

[39] Modelica official site: https://modelica.org/

[40] Frigo S., Pasini G., Marelli S., Lutzemberger G. et al., "Numerical Evaluation of an Electric Turbo Compound for SI Engines" SAE Technical Paper 2014-32-0013, 2014, doi:10.4271/2014-32-0013.

[41] G. Kouroussis, P. Dehombreux, O. Verlinden, "Vehicle and powertrain dynamics analysis with an automatic gearbox", Mechanism and Machine Theory 83 (2015), 109-124.

[42] Modelica Libraries official site: https://modelica.org/libraries

[43] C. Lv, J. Zhang, Y.Li, Y. Yuan, "Mechanism analysis and evaluation methodology of regenerative braking contribution to energy efficiency improvement of electrified vehicles", Energy Conversion and Management 92 (2015), 469-482.

[44] BMW official site: http://www.bmw.com/com/en/insights/technology/technology_guide/articles/ mm_brake_energy_regeneration.html

[45] Common Artemis Driving Cycle (CADC) site: http://www.dieselnet.com/standards/cycles/ artemis.php

[46] Simpkin R., D’Ambrosio C., Simonsson J. et al., Energy Efficient Vehicles for Road Transport, Transport Research Arena - Europe 2012, Athens (Greece), 23-26/4/2012. 